\title{
Nuevos modos de comprender el diálogo intercultural y el contacto entre lenguas en China a principios del siglo XX: los aportes desde la traducción y la historia.
}

Verónica Noelia Flores ${ }^{1}$

Escuela de Estudios Orientales, Universidad del Salvador

Ensayo. Material original autorizado para su primera publicación en el Journal de Ciencias Sociales, Revista Académica de la Facultad de Ciencias Sociales de la Universidad de Palermo.

Recibido: 11-8-2015

Aceptado: 2-10-2015

\section{Resumen}

Frente a la riqueza histórica, la pluralidad cultural y la diversidad lingüística de cada pueblo, se presenta para el investigador social el desafío ineludible de lograr la comunicación y el diálogo horizontal, de crear para ello un espacio de encuentro y de comprensión mutua. En el marco de este problema y con vistas a aportar al diálogo entre saberes y disciplinas, el propósito de este ensayo es indagar en las posibilidades, límites e implicancias que comporta el lenguaje como instrumento mediador en este proceso de conocimiento del otro. A fin de reflexionar sobre algunas respuestas posibles a tal desafío, proponemos aquí una consideración teórica acerca del lenguaje, en el marco de los intercambios culturales y de los contactos entre lenguas ocurridos en China a principios del siglo XX.

Con la intención de elaborar otras maneras de concebir la historia cultural de estos encuentros, buscaremos aquí articular dos experiencias concretas de trabajo sobre el nivel del lenguaje: la traducción entre lenguas y la escritura de la historia. Lejos de ser neutrales, ambas tareas buscan la comprensión del otro a través del recurso que brindan las palabras, signos materiales, concretos e históricamente situados en el contexto de su enunciación. A partir de los aportes renovados de la traducción y de la historia, se intentará por lo tanto ofrecer una nueva mirada acerca de los modos de comprender el diálogo intercultural entre China, Japón y Occidente durante este período. El enfoque paradigmático de Lydia Liu (1995) en su obra Translingual practice nos permitirá finalmente ejemplificar una clave historiográfica de lectura de estos cambios en el sentido de la articulación entre traducción e historia que aquí proponemos.

Palabras clave: diálogo intercultural, lenguaje, traducción, historia.

\footnotetext{
1 Lic. en Historia (FFyL, UBA). Investigadora y Profesora Adjunta regular de la Escuela de Estudios Orientales, Universidad del Salvador. Miembro del Grupo de Estudios del Este Asiático (IIGG, UBA). Miembro del Grupo de Estudios sobre India (CARI). Doctoranda en Historia y Teoría de las Artes (FFyL, UBA). Becaria del CONICET. E-mail de contacto: veronican.flores@usal.edu.ar
} 


\section{Abstract}

Faced with the historical depth of each people, their cultural pluralism and linguistic diversity, it is an unavoidable challenge for the social researcher to achieve communication and horizontal dialogue, as well as to create for this purpose a space of encounter and mutual understanding. In order to contribute to the dialogue between different knowledges and disciplines, the aim of this essay is to explore the possibilities, limits and implications that involves language as a mediating instrument in this process of comprehension and knowledge of the other. To reflect on some possible answers to this challenge, we propose here a theoretical regard about the rol of language, in the frame of cultural exchanges and contacts between languages occurred in China in the early twentieth century.

With the intention of developing other ways of conceiving the cultural history of these encounters, we will seek to articulate here two specific experiences working on the level of language: translation between languages and writing of history. Far from being neutral, both performing tasks seek understanding others through words, which are material, concrete and historically situated signs in the context of its enunciation. From the contributions of translation and history, it will try therefore to offer a new perspective on the way of understanding intercultural dialogue between China, Japan and the West during this period. Finally the paradigmatic approach of Lydia Liu (1995) in her book Translingual practice will allow us to exemplify a key historiographical reading of these changes in the direction of the joint between translation and history we proposed here.

Keywords: intercultural dialogue, language, translation, history.

\section{Introducción}

Mientras se investiga, ya sea a través de documentos y registros recientes, de otros tiempos o a través de encuentros cara a cara, el investigador se enfrenta con sujetos que viven y piensan en otras lenguas y otras culturas. Frente a esta situación, se presenta el desafío ineludible de lograr la comprensión, la comunicación con el otro -ese que es radicalmente otro en la distancia o el tiempo-, de crear para ello un espacio de encuentro y de comprensión mutua. El problema de acceder al conocimiento de ese otro radical, a la comprensión de la realidad desde las Ciencias Sociales, nos remite aquí a la pregunta por la validez de ese conocimiento construido, a los criterios de verdad que se elaboran para sostenerlo y, en última instancia, a la pregunta misma por el lenguaje, como instrumento de comunicación y comprensión humana.

El objetivo de este ensayo es indagar, a través de un recorrido teórico, en las posibilidades, límites e implicancias que supone el papel mediador del lenguaje en el proceso de conocimiento. Con vistas a señalar 
algunas respuestas a aquel desafío en el oficio de la investigación, elaboramos un camino de posibles respuestas que pone en relación a la traducción y la historia, dos campos disciplinares que, aun con sus especificidades, consideramos que comparten en su epistemología y métodos de trabajo el interés y las dificultades de comprender y comunicar la experiencia del otro en el tiempo.

Para dar forma a este trabajo, trazaremos tres etapas en nuestro recorrido: la primera, más general, dedicada a revisar las posiciones que desde la filosofía del lenguaje han reflexionado sobre el concepto y el acto de traducir; la segunda, orientada a trazar la relación entre traducción e historia considerando algunas características de sus modos de trabajo y estrategias de acercamiento al objeto de estudio y, por último, una tercera parte dedicada al problema de la escritura de la historia como narrativa y a los cambios surgidos en la historiografía reciente a partir de la consideración del lenguaje en el enfoque epistemológico de sus investigaciones. Presentaremos finalmente como ejemplo paradigmático de estos cambios el abordaje que propone Lydia Liu (1995) en su obra Translingual Practice, como un modo diferente de comprender los contactos entre lenguas y el diálogo intercultural ocurrido entre China y Occidente durante las primeras décadas del siglo XX.

\section{Dimensiones de la traducción como concepto y como acto: comunicación, comprensión y hospitalidad lingüística}

El fenómeno de la traducción, desnaturalizando la espontaneidad de su constante devenir en el tiempo, es complejo y multifacético. Su abordaje, desde una perspectiva social y cultural, nos remite tanto al estudio del lenguaje y de la comunicación humana como a los modos diversos de concebir el mundo. Se trata de un espacio de producción de sentidos cuyo análisis permite recorrer momentos de encuentro, confrontación y diálogo constructivo entre diferentes culturas. Por esta razón nos interesa comenzar este trabajo a partir del estudio de la traducción, como concepto y como acto, entendiendo su definición como una guía para comprender mejor las vías de contacto entre lenguas en China a principios del siglo XX.

George Steiner en su célebre libro Después de Babel (1995) afirma que los acontecimientos de traducción existen y se replican sucesivamente ya que todo proceso de significación del mundo, de nuestras experiencias en él y con los otros, comporta en sí mismo un proceso de traducción. "Pensamos y significamos la realidad a través de traducciones", y que esto es así debido a que hablamos diferentes lenguas, pero también porque "cada lengua posee formas de pensamiento particulares y diversas que permiten organizar, entender y valorar el mundo de manera diferente" (Steiner, 1995, p. 71). En el marco de esta pluralidad, Paul Ricoeur (2005) por su parte, señala las dificultades concretas que se presentan a 
quien oficia de traductor, pero también pone de relieve la importancia de la "pulsión de traducir", de ese "deseo que va más allá de la imposición y de la utilidad" (Ricoeur, 2005, p. 41). Entendiendo, a partir de estas premisas, que la reflexión sobre la traducción es inescindible de la práctica de traducir, nos preguntamos ¿cómo es posible definir este trabajo?, ¿en qué consiste y qué dificultades y posibilidades plantea?

Lejos de existir entre las teorías del lenguaje una definición única en la que se recojan todos los matices, hay diferentes entradas al problema planteado por el acto de traducir. Si partimos de la perspectiva universalista que sostiene que la traducción existe y que efectivamente es posible, podemos encontrar algunas definiciones. Veamos las que se desprenden de la clasificación que provee Roman Jakobson al considerar diferentes formas de interpretar un signo verbal. Para este autor, una definición en sentido estricto, es la de la traducción entre lenguas (traducción interlinguística o traducción propiamente dicha) que implica una interpretación de signos verbales mediante otra lengua (Jakobson, 1987, p. 429). Esta definición reconoce el fenómeno ineludible de la diversidad de las lenguas y el papel mediador del lenguaje en el proceso de comunicación humana, al transmitirse a través de ella un determinado mensaje o conjunto significante de una lengua a otra.

En un sentido más amplio, traducir también supone hacer frente a otro fenómeno social primordial que es el de la heterogeneidad y riqueza de sentidos que proveen las lenguas en sí. La práctica de la traducción puede involucrar entonces la interpretación de un mensaje dentro de una misma comunidad lingüística. Es lo que Jakobson llama traducción intralingüística o reformulación (rewording): una interpretación de signos verbales mediante otros signos de la misma lengua (1987, p. 430). Por último, este autor reconoce la traducción intersemiótica o transmutación, que supone el pasaje de un código lingüístico a otro no lingüístico.

Si permanecemos en el contexto verbal que proponen las primeras definiciones de Jakobson, el significado de una palabra no es sino su traducción a otras palabras. Así, tanto en el caso de la traducción interlinguística como de la intralingüística, el acto de decir una cosa en términos de otra es un proceso de significación, un movimiento de búsqueda y traslado de sentidos. Nos movemos constantemente de los parámetros de otros a los parámetros propios. Steiner en este mismo sentido señala: "en suma, dentro o entre las lenguas, la comunicación humana es una traducción" (Steiner, 1980, p. 64). Observamos entonces la importancia de la traducción, en un sentido amplio, para la comunicación en general y para la comunicación intercultural en particular, ya que sin ella sería imposible lograr que una persona comprendiese los objetos, las situaciones y los fenómenos que no forman parte de su cultura. Entendemos 
el diálogo intercultural como un proceso horizontal de construcción, interacción y transformación entre culturas (Grimson, 2000).

La traducción, desde las concepciones de Steiner y de Ricoeur, se presenta como un proceso de comunicación-comprensión del otro, de respeto por su singularidad y no como un mero asunto de transferencia de significados entre los lenguajes, dentro del horizonte de una traducibilidad absolutamente pura, transparente e inequívoca. En este sentido, traducir implica una voluntad y un trabajo difícil de acercamiento y comprensión del otro. Es precisamente este reconocimiento, como nos advierte Steiner, el que introduce una dimensión ética en la comunicación humana. Antes de volver sobre este punto con Ricoeur, revisemos algunas implicancias del acto de traducir para entender cómo opera la singular posición del traductor.

La existencia profusa de traducciones entre lenguas, como mencionamos antes, verifica una paradoja del lenguaje que se describe en el relato mítico de Babel: el fenómeno de la diversidad y pluralidad de las lenguas. En contra del mito totalitario de una lengua universal -cuya posibilidad habrían perdido como castigo divino los hombres, condenados a la confusión y a la dispersión- Walter Benjamin señala la riqueza cultural que entraña para los seres humanos el hecho de la pluralidad y la heterogeneidad de las lenguas. Más que una pérdida e imposibilidad de comunicación, para este autor el carácter múltiple de las lenguas supone un caudal infinito de significados. Por esta razón, el sentido no se encuentra en la observación directa del objeto sino en la articulación que cada cultura -como sistema simbólico- establece entre el objeto como referente, como objeto "pensado" y "la manera de pensar" -de simbolizar- de quien la piensa. La ardua pero redentora tarea del traductor se cifra entonces en "encontrar en la lengua -o la cultura- a la que se traduce una actitud que pueda despertar en dicha lengua -o en dicha cultura- un eco del original" (Benjamin, 1999, p. 83).

En ese proceso que describe Benjamin reside, no obstante, uno de los aspectos más problemáticos de la traducción: el reconocimiento de la palabra extranjera como una posibilidad de conocimiento de la propia lengua. En la articulación de dos lenguas hay una operación deliberada de desciframiento e interpretación, una búsqueda de inteligibilidad que se transita, de acuerdo a Ricoeur, como una "prueba" para el traductor. Así,

Dos términos son puestos en relación por el acto de traducir: lo extranjero -término que abarca la obra, el autor, su lengua- y el lector destinatario de la obra traducida. Y entre ambos, el traductor, que transmite, que hace pasar el mensaje de un idioma a otro. En esa incómoda situación de mediador reside la prueba en cuestión (Ricoeur, 2005, p. 19). 
La incomodidad del traductor radica en su necesidad de afrontar una doble resistencia, implícita en el fenómeno insoslayable de la heterogeneidad de las lenguas. El traductor se enfrenta a la presunción de intraducibilidad que impone la lengua extranjera. En esta situación, el texto a traducir ofrece su resistencia mostrándose confuso e inescrutable mientras que la irreductibilidad de los campos semánticos se vuelve manifiesta. La idea de un original imposible de duplicar se presenta como primer impedimento, de la mano del rechazo que también supone el etnocentrismo de la lengua receptora. La salida de esa situación de "incómoda mediación" se produce a través de un duelo impuesto que acepta el traductor frente a la imposibilidad de una traducción absoluta. Esta pérdida de certidumbre es un trabajo de conquista sobre el ideal de traducción perfecta: no existe una obra capaz de traducirse a la perfección como tampoco existe aquella lengua universal y pura de cuya búsqueda vana nos prevenía Benjamin. Es sólo a través de ese renunciamiento, como una contingencia aceptada, como el traductor supera la diferencia irreductible entre lo propio y lo extranjero. Paradójicamente, como afirma Ricoeur, aceptar la irreductibilidad de lo otro habilita una multiplicidad de posibilidades en la creación de sentidos. Frente a esta paradoja, la "felicidad de la traducción" reside en la posibilidad que brinda el oficio de descubrir y crear nuevos sentidos dándole un lugar a la alteridad pero también al extrañamiento propio.

Aquí se hace más claro el argumento que expone Ricoeur al describir el acto de hospitalidad lingüística que se realiza a través de la traducción. Se trata no sólo de un trabajo intelectual sino también de un proyecto ético, en tanto comporta "la capacidad de abrir la puerta y acoger lo extranjero, de recibirlo en la propia casa" (Ricoeur, 2005, p. 28). Gracias a la diversidad de las lenguas nos es dado pasar por la experienciaprueba de lo extranjero. El "deseo de traducir" desafía y atraviesa en la experiencia concreta al fantasma de la imposibilidad, y al hacerlo supera de algún modo la incomunicación y la separación radical respecto del otro. En este mismo sentido Ricoeur piensa el mito de Babel, ya no como el castigo insalvable de un dios despiadado, sino como testimonio de una separación originaria, que ya está presente en la separación de los elementos, en la expulsión del paraíso, en el fratricidio de Caín. Todos éstos son hechos que hacen de la fraternidad, por lo tanto, un proyecto ético y humano, y no un hecho religioso o natural.

Es esa articulación que elabora el traductor, buscando respetar las especificidades de cada lengua, la que resuelve en términos prácticos el problema planteado por las oposiciones traducibilidad/intraducibilidad, universalidad/relativismo como barreras teóricas que obstaculizan el encuentro con el otro y el reconocimiento de sí mismo. El traductor transforma entonces su propio espacio para incorporar el sentido y las palabras del otro. 


\section{Condiciones del lenguaje y posibilidades del oficio: contextualización y creación de equivalentes en los métodos de la traducción y la historia.}

Toda traducción propone, en palabras de Ricoeur, una "reflexión de la lengua sobre sí misma" (Ricoeur, 2005, p. 50). Aun renunciando de antemano al ideal de una traducción absoluta, tal ejercicio supone un reto difícil en la práctica. Para traducir una palabra desconocida es necesario disponer, evaluar y poner en juego un conjunto de signos lingüísticos que ofrezcan referencias, que permitan establecer relaciones y construir sentidos. Esta búsqueda y utilización de recursos y competencias lingüísticas e interpretativas para entender un determinado mensaje se resuelve de manera espontánea en la vida cotidiana. No obstante, al reflexionar sobre esta puesta en juego de recursos lingüísticos como un oficio que se construye, junto con el reconocimiento de los procedimientos cotidianos de la lengua viva (puesta en acto en una determinada comunidad de hablantes), se refuerza la pregunta por el método, por las técnicas e instrumentos de trabajo de los que dispone el traductor para lograr la comprensión de lo que desconoce.

Valentín Voloshinov sostiene que al trabajar con el lenguaje tratamos con signos que tienen una entidad material y que, gracias a esta condición, pueden ser analizados a través de un método de estudio objetivo (Voloshinov, 1976, p. 21). ¿Cómo trabaja el traductor sobre su objeto de estudio? ¿Cómo conoce sus dimensiones de análisis? ¿Qué estrategias de avance y control lleva adelante? De acuerdo con Steiner, los instrumentos de acercamiento y especulación del traductor están constituidos por "una compleja combinación de conocimientos, familiaridad e intuición recreativa" (1995, p. 45). Sabemos que el proceso metodológico en el curso de una investigación comporta una puesta en discusión de saberes y conceptos, un diálogo que exige una permanente toma de decisiones para utilizar adecuadamente los instrumentos teóricos que sirven de herramientas.

El carácter polisémico de las lenguas es un aliciente: siempre es posible decir lo mismo de otra manera. Esto es lo que hace el traductor de lenguas extranjeras. Ese decir de otro modo es consecuencia y riqueza del poder creativo del lenguaje que permite crear alternativas. Explicar el significado de una expresión con otras palabras es siempre fruto de una interpretación que puede variar en función de quien la formule. Una enunciación sobre la realidad -un modelo construido a partir de signos- no es la realidad en sí, sino un modo entre muchos otros posibles de expresarla. Ante la negatividad que suponen los signos frente a las cosas y frente a la pluralidad de sentidos que aportan las lenguas en su infinita capacidad expresiva, el sentido de lo dicho en la vida cotidiana se va delimitando por el uso, por las relaciones vivientes que dan significación a esas palabras que intercambian los hablantes (Ricoeur, 2005, pp. 51-52). Por esta razón, resulta desesperada y pobre la traducción que permanece en el nivel literal de lo expresado. El "deseo de traducir" 
mira más allá del contenido manifiesto, pero ¿cómo dar cuenta de los matices, de las diferencias o incluso en las semejanzas de sentido entre las palabras sin caer en reduccionismos?

Si bien no disponemos de un método universal y de unas reglas fijas que aplicar y repetir con éxito, una estrategia de trabajo válida al traducir es la del recurso al contexto. Descubrir el contexto de uso de las palabras, "dominar el entorno temporal y local del texto al que uno se enfrenta [...] allana la comprensión en cualquier punto" (Steiner, 1995, p. 42). Esta estrategia supone un análisis en la traducción que toma en cuenta el factor temporal asociado a la entrada en acción del lenguaje, que reivindica aquella riqueza de sentidos posibles en un discurso, pero también supone una mirada más atenta para reconocer su carácter históricamente situado (lo que los lingüistas llaman estructura diacrónica). En este punto, podemos reconocer que los modos de trabajo del traductor y del historiador se conectan, pues ambos pisan sobre el mismo terreno. Si bien en niveles distintos, parecen realizar la misma operación hermenéutica. En la contextualización ambos emprenden un movimiento que va desde la cultura y el medio en que se inscribe un determinado discurso a las oraciones y las palabras que lo integran, y no a la inversa.

A la luz de la semiótica de Peirce, la realidad del pasado, al igual que la del presente, es siempre una realidad pensada por alguien. "Traducimos cuando entramos en contacto oído o leído con el pasado" (Steiner, 1995, p. 44). En este sentido, toda comunicación con los saberes de antaño comporta una relación de diálogo y una traducción. Si la historia es un "acto verbal", como señala Steiner, "que lee y reubica selectivamente los vestigios del pasado" (1995, p. 46), ¿de qué manera se construye en una investigación ese contexto de identificación verbal que permite hacer aparecer la voz de la historia? ¿Es posible pensar la traducción, en un sentido amplio, como metáfora de la construcción verbal que realiza el historiador para dar sentido a las fuentes? ¿Cómo éste formula a partir de un acto de traducción los conceptos y las interpretaciones que definen una época?

Del mismo modo en que no existe una lengua universal que habilite traducciones absolutas entre las lenguas o al interior de ellas, tampoco existe una historia total: un relato que pueda contener literalmente en sus márgenes el registro completo de todos los acontecimientos del pasado. La organización semántica de los recuerdos y memorias ha sido pensada, elaborada y codificada laboriosamente, de distintas maneras por diversos hombres, grupos y culturas. Dan cuenta de ello las sucesivas composiciones del pasado que han llegado hasta nosotros y que continúan siendo trabajadas con vivacidad por quienes reconocen en ellas un sentido más o menos evidente que los acerca a su propio presente. Por esa razón, en buena medida y como algo inherente a la práctica misma del oficio, todo historiador traduce sus registros y todo traductor historiza su objeto de estudio. Es el recurso al contexto lo que le permite tanto a uno como al otro, percibir el sentido que ha tomado una palabra o una frase en determinada circunstancia del discurso. Este gesto que 
apela no sólo al contenido sino también a las formas conduce a intentar la traducción sentido por sentido. Se construyen así, de modo precario y riesgoso, las equivalencias significativas que hacen posible la comunicación humana, sin negar la pluralidad de sentidos posibles. Son esos puentes, que Ricoeur llama "comparables semánticos" o mejor aún, "equivalencias sin identidad", los que permiten superar la distancia entre distintas lenguas, que posibilitan atravesar el obstáculo de los lenguajes en apariencia inconmensurables, pero también las pretensiones esencialistas y atemporales de las categorías universales. Lejos de ser equivalencias de tipo lógico-matemático, son por el contrario términos, categorías o expresiones que buscan una correspondencia teórica temporal, fluida, sujeta a revisiones de sentido. Se trata de puentes que se transitan en ambos sentidos, permanentemente y con fluidez, sin ser fijas ni absolutas pues no existen dos campos semánticos iguales. Una buena traducción, afirma Ricoeur, es "una equivalencia sin identidad", ya que "no puede apuntar sino a una equivalencia presunta, no fundada en una identidad de sentido demostrable. Esta equivalencia sólo puede ser buscada, trabajada, presupuesta" (Ricoeur, 2005, p. 49). Aquí se vuelve evidente un hecho que se desprende de este trabajo constructivo sobre el nivel del sentido: el traductor no descubre esos equivalentes, sino que los crea. Es el trabajo de la lengua sobre sí misma, el proceso de traducción-construcción de lo comparable a través del sentido, lo que resuelve el enigma que suponen las equivalencias presuntas en un texto o un relato.

Para retomar la cuestión del método, volvemos a la pregunta “¿cómo se construye - desde la historia y desde la traducción- ese relato que vuelve inteligible las palabras y los hechos?" Entendemos que no existen buenas traducciones artificiales ni tampoco historias significativas hechas por máquinas. Tampoco existen dos lecturas exactas de un mismo hecho o fenómeno histórico ni dos traducciones idénticas de un texto. En tanto cada una se realiza desde un punto de vista único, cada elaboración de sentidos es singular. Lo que interesa aquí es la "interpretación", entendida como "lo que da vida al lenguaje más allá del lugar y el momento de su enunciación o transcripción inmediata" (Steiner, 1995, p. 44).

La materia en común que poseemos para comunicar lo estudiado es el lenguaje, con su acervo inagotable de sentidos y posibilidades expresivas. Con el lenguaje no sólo podemos decir algo sobre la "realidad objetiva" de un texto o de un determinado acontecimiento del pasado, sino que también podemos ocultar, desdecir, negar, dejar sin decir. La traducción tanto como el relato histórico reviste un carácter singular y expresivo como construcción hecha, no dada de antemano. Esto es posible, como plantea Steiner siguiendo a Saussure-, porque existe una contradicción fundamental entre el lenguaje y el mundo, una “inadecuación” que es a la vez el límite y la posibilidad humana de comunicar lo que es y al mismo tiempo de decir lo que no es, de construir nuevos sentidos (Steiner, 1995, p. 28). Al traducir se piensan y se construyen las relaciones hipotéticas que hacen posible y significativa una comparación. Podemos valernos 
de equivalentes presupuestos (pues los términos de la comparación se construyen sobre la base de equivalencias lingüísticas percibidas como tales), pero tal presuposición no garantiza una adecuación perfecta e inmutable sino que sólo nos concede un andamio teórico variable, sujeto a revisiones, ajustes, críticas y cuestionamientos.

Como una consecuencia del renunciamiento al ideal de una traducción perfecta se sugiere, por lo tanto, esta estrategia de avance postulando equivalencias significativas aunque hipotéticas. Esta vía, que nos propone una elaboración cuidadosa de la traducción, sopesando matices y admitiendo diferencias no reducibles entre los conceptos, resulta importante para los estudios sociales, culturales e históricos que requieren establecer relaciones de comparación entre culturas y comunidades lingüísticas diferentes. Esta mirada nos alerta a no perder de vista los fundamentos materiales de esos "equivalentes sin identidad" que se construyen a través de la traducción. De no asumir este recaudo, al surgir la inexistencia de un concepto equivalente esta situación de singularidad puede parecer impensable en lo teórico y por lo tanto ser negada en lo práctico, interpretándose como una "falta", una carencia, una deficiencia de la cultura estudiada.

Esta observación se aplica también al uso problemático de ciertas categorías filosóficas occidentales que se presentan como dogmas de verdad y universalidad, imponiendo una prioridad discursiva sobre la cultura estudiada. La construcción de estas categorías analíticas en estudios comparativos con frecuencia dice más sobre el sujeto que investiga que del objeto de su investigación. Pero ¿qué se gana y que se pierde con estas categorías que se pretenden totalizadoras y con esas traducciones que niegan lo que desconocen? Esta situación nos revela el carácter contingente, precario y riesgoso de las traducciones, pero también nos habilita a ver en esta condición una vez más el proyecto ético que apela al traductor así como la riqueza de sentidos posibles que se inscriben en los elementos "no-traducibles" literalmente de la lengua, de las personas y de las culturas estudiadas.

La reflexión que nos alerta frente a estas contingencias es inescindible de la práctica donde esas equivalencias supuestas puedan verse funcionando, aun provisoriamente, para facilitar la comprensión mutua. En cualquier caso, evitar el camino de las construcciones sistemáticas que se apoyan en un pretendido carácter absoluto de los conceptos es un modo no sólo de reconocer esa frágil condición de la traducción sino también de ver las posibilidades que comporta su verificación a partir de nuevas y posibles traducciones que desplieguen y recreen su riqueza expresiva. 


\section{La mediación del lenguaje en las nuevas escrituras de la historia}

\section{a) De la crisis y la dispersión a la renovación historiográfica}

En el marco de estas discusiones sobre el lenguaje, cobran relevancia ciertas preguntas que atañen a la polémica cuestión de la verdad del conocimiento y a los criterios de validez que funda y mantiene cada disciplina en el marco más amplio de una determinada comunidad científica: ¿por qué, para quién y desde qué lugar se produce conocimiento?, ¿cómo se sostiene la legitimidad de este conocimiento? En el caso de la historia, la intención de verdad se basa en el procedimiento de los documentos, que son huellas del pasado, pero también en los modelos de inteligibilidad que construyen su interpretación.

El pasado es "una construcción del lenguaje", sostiene Steiner, pero a su vez, el relato histórico construye una determinada representación del pasado (Steiner, 1995, p. 38). Esta última afirmación, lejos de resultar espontánea, se puso de manifiesto a partir de las transformaciones que atravesó la disciplina histórica en los últimos treinta años del siglo XX, a raíz de la entrada en crisis del paradigma estructural funcionalista, pero sobre todo de las discusiones que introdujo el giro lingüístico (linguistic turn) y, particularmente los nuevos modos de hacer historia a partir de los años ochenta hasta la fecha.

La relativización de las certezas, que en su versión más extrema plantea el carácter ficcional de toda narrativa sobre el pasado, implicó la puesta en duda de las formas más globalizantes y estructuradas de aproximación a los procesos históricos. De la crisis de los "grandes relatos" surgió entonces la idea de una historia desdoblada como saber y como discurso. Roger Chartier advierte que si bien esta perspectiva ha ganado un notable consenso en las últimas décadas, la función de "representancia" de la historia (que se define como la "capacidad del discurso histórico para representar el pasado") es "constantemente cuestionada, sospechada, por la distancia introducida necesariamente entre el pasado representado y las formas discursivas necesarias para su representación" (Chartier, 2007, p. 34). La historia, de acuerdo con este autor, no es ni puede ser, la restitución del pasado, del acontecimiento en sí, sino tan sólo una de sus representaciones, pero esta representación es la de un orden específico, que no es el de la ficción ni el de la novela. Aquí se presenta un dilema: si bien la historia es una representación del pasado que toma para su expresión la forma escrita, siempre retorna al problema de la "verdad", con el afán de preservar un modo de conocimiento verificable, aceptable y compartido.

Con la atomización y dispersión de los referentes historiográficos a partir de los años setenta, el tema de la centralidad de "lo verdadero", ya sea en referencia a una teoría o a un conjunto de evidencias históricas, se ha vuelto un problema inverosímil. Esta discusión obliga a retomar la cuestión de cómo pensar un estatuto 
de cientificidad específica que contemple a favor de la validez del conocimiento histórico su pertenencia al género narrativo. Dicho en otros términos, ¿cómo se acredita entonces la representación histórica del pasado?

Ricoeur (1995) en su obra Tiempo y narración I propone una respuesta de orden epistemológico a esta pregunta, que consiste en articular las tres fases de una operación historiográfica: el establecimiento de la prueba documental, la construcción de la explicación (que se apoya sobre la conceptualización, la búsqueda de objetividad y la reflexividad crítica) y finalmente, la puesta en forma de escritura. Este último momento, el de la escritura de la historia -para emplear el título de la obra de Michel de Certeau- no es exterior a la concepción y a la composición de la historia; "no constituye una operación secundaria sino que es constitutiva del modo histórico de comprensión" (Ricoeur, 1995, p. 269). En este sentido, la historia es intrínsecamente historiografía, pero ésta no subsume los hechos dentro de leyes (como lo haría la física) sino que los integra dentro de tramas narrativas. El campo de la argumentación narrativa donde esta operación se realiza (de modo formal, explícito y discursivo) es mucho más amplio que el de las leyes generales. Vale decir que los modos de argumentar son igualmente numerosos ya que comportan una determinada concepción sobre lo que se debe esperar de la explicación histórica, pero también una determinada reflexividad crítica. Ricoeur caracteriza entonces la construcción de la trama histórica por medio de "toda una gama de intercambios entre paradigmas e historias singulares" (Ricoeur, 1995, p. 277). La comprensión narrativa que produce la historia, a diferencia de las explicaciones formuladas a partir de leyes y regularidades, es una forma de mediación abierta, inacabada e imperfecta. La temporalidad de las fuentes y huellas del pasado es establecida por el historiador organizando a través del lenguaje entidades de referencia y construyendo vínculos de sentido entre ellas. Por esta razón, del mismo modo que el traductor, el historiador renuncia al ideal de una "mediación total", de una narración totalizante, emprendiendo la comprensión del pasado a través de la construcción de una trama de sentidos posibles, de relaciones significativas, de perspectivas cruzadas.

En ese proceder, se va haciendo presente la explicación teórica que se fundamenta a través de la referencia a un modelo, a un sistema de teorías y principios desde el cual se construyen tales relaciones. La teoría nos ofrece, por lo tanto, una forma de mediación que nos permite avanzar en la comprensión del objeto de estudio, pero de ningún modo lo sustituye. En este sentido, podemos decir que cada teoría muestra para el objeto de estudio construido, sus aportes tanto como sus limitaciones. Del mismo modo, cada explicación teórica en el curso de un proceso de investigación comprende un contexto y un fin.

Al estudiar un determinado estado del conocimiento sobre un tema nos encontramos con un "entramado de voces", tomando la clásica imagen de Roland Barthes, cuya riqueza reside en los diferentes sentidos que 
aporta cada voz a la comprensión del problema que abordamos. Lo interesante de trabajar con este entramado de discursos, y el desafío que a su vez comporta, es historizar los conceptos y las discusiones que los sostienen. En este sentido, Bajtín argumenta que un discurso es dialógico, no monologal, pues su sentido se constituye en respuesta a otros discursos. Esta es precisamente la forma en que se avanza en un proceso de investigación y se produce conocimiento: en diálogo con otros conocimientos y saberes.

En relación con el panorama de atomización de la producción historiográfica que mencionábamos antes, visto desde otra perspectiva, podríamos considerar también que ha habido en las últimas décadas acercamientos que han redefinido espacios intelectuales compartidos. Los cambios en el enfoque epistemológico de la historia (que afirman que el conocimiento es un acto de comprensión y no de descubrimiento) han permitido repensar la importancia de los propios sujetos en tanto actores sociales, prestando especial atención a sus prácticas y experiencias, así como al análisis de sus representaciones del mundo, para comprender de este modo los espacios de agencia, participación y libertad que los constituyen, escapando al corset de las estructuras e ideologías.

Esto implicó, a su vez, el surgimiento de nuevas áreas de interés en el campo historiográfico (como la historia cultural, la historia de las mujeres, la historia oral, la historia desde abajo, entre muchas otras), el redescubrimiento y redefinición de otras áreas (tales como la historia oral, la historia política y la historia de las ideas), y el trabajo sobre nuevas escalas de análisis, particularmente la microhistoria (Burke, Gil \& Martin, 2003). Se han problematizado en estos nuevos espacios nociones, acciones y procesos que forman parte de una "realidad no transparente, concebida en su contingencia y su misterio" (Chartier, 2007, p. 42). Visto de este modo, la historiografía ha encontrado rumbos inéditos que abonan el terreno para seguir pensando la narración histórica como una trama abierta, cuya construcción se realiza en diálogo comprensivo con otros saberes.

\section{b) Comprensión entre pueblos, traducción entre lenguas: un ejemplo en la historia de los contactos entre}

\section{China y Occidente}

Para presentar un ejemplo de estos cambios en los modos de concebir el lenguaje y sus implicancias en la construcción del relato histórico, veamos algunas transformaciones que han ocurrido en el campo de la historia sociocultural de China contemporánea. Podemos mencionar aquí el importante desarrollo que ha ocurrido en los estudios históricos recientes en relación con las primeras décadas del siglo XX. El interés historiográfico, tanto dentro como fuera de China por revisar este período (tanto los documentos de la época como lo que se ha escrito sobre ellos) ha sido motivado por varios factores. Entre ellos, el acceso 
antes negado a fuentes y archivos documentales chinos desde fines de la década del setenta y el advenimiento de nuevas teorías en el campo de las Ciencias Sociales que aportaron nuevas miradas sobre temas como el nacionalismo, la construcción identitaria y las formas de agencia y gobernabilidad en el período de la República Nacionalista en este país. Una de las tendencias historiográficas más fértiles que ha surgido a partir de estos cambios es la que pondera el análisis de la experiencia colectiva y la vida cotidiana de los individuos y grupos a través de los registros de su cultura material, para comprender la formación de "identidades negociadas", no estáticas en su determinación sino en conflicto a lo largo del tiempo (Duara, 1996).

Esta mirada renovada resulta útil para volver a pensar la historia y el desarrollo cultural de los pueblos no europeos en sus formas de contacto y relaciones conflictivas con Occidente entre fines del siglo XIX y principios del siglo XX. El enfoque de estos nuevos estudios considera el cambio histórico de la modernidad en China, clave de este período, como un proceso de confrontación, de resistencias y adaptaciones, y no de transición unilineal hacia la meta del estado-nación moderno y la sociedad industrial europea.

Más aún, lo interesante de estos nuevos estudios es que tratan la experiencia de "lo moderno" chino no como un fenómeno ya dado o presupuesto por el contacto con Occidente, sino como una construcción discursiva, y por lo tanto históricamente situada. En este sentido, por ejemplo, la obra de Lydia Liu (1995) Translingual practice. Literature, national culture and translated modernity resulta paradigmática de este nuevo modo de abordar la historia social y cultural de este período en China. En este trabajo Liu propone como metodología historizar las prácticas del lenguaje e indagar en la trayectoria discursiva de los conceptos que construyeron el discurso sobre lo moderno en China entre 1900 y 1937. Liu observa un momento temprano de intercambio histórico entre China y Occidente con relación a las prácticas del lenguaje pues analiza los primeros contactos durante esos años del idioma chino con el japonés moderno y otros lenguajes extranjeros.

Ya desde el último cuarto del siglo XIX, las traducciones entre lenguas se habían extendido entre los círculos letrados chinos como un fenómeno cultural amplio que acompañó la búsqueda de comunicación y comprensión del otro -extranjero, occidental-, pero también constituyéndose como un modo de orientación y de reflexión sobre sus propios valores, condiciones y posibilidades frente al cambio. Quienes realizaron estas primeras traducciones -entre los más notables, se destacan Yan Fu, Lin Shu, Yu Dafu, Lu Xun y Guo Moruo- fueron jóvenes interesados en adaptar a la tradición china las nuevas ideas provenientes de Europa y Japón, considerados como modelos exitosos de modernización y progreso.

A partir de las experiencias reformistas durante el último período del Imperio, los conceptos de evolucionismo, liberalismo, ciencia y democracia se instalaron en las discusiones intelectuales de esta época 
a partir de las traducciones al chino de obras filosóficas y literarias en japonés y otros idiomas europeos. En el marco de la decadencia política del imperio y del declive cultural de los antiguos bastiones de la tradición confuciana en China, el imperativo de forjar "un hombre nuevo" fue lo que condujo a esta generación de jóvenes a dejar atrás la formación clásica que habían recibido y a viajar al extranjero para nutrirse de nuevas ideas que pudiesen contribuir a la recuperación del país.

En este período, fue central la influencia del japonés moderno entre los intelectuales y estudiantes chinos, que al volver a su país introdujeron un importante número de términos prestados, adaptaciones y neologismos. Hubo reinvenciones y nuevos caracteres chinos que se formaron a través de la mediación del japonés moderno para designar términos europeos. Las transformaciones a nivel político y cultural a las que estuvieron expuestos tanto China como Japón durante estos años volvieron más conscientes a sus intelectuales acerca de las posibilidades y limitaciones de sus propias formas de expresión y representación del cambio.

Lydia Liu propone para repensar este contexto el concepto de "práctica translinguística" (translingual practice), una noción que permite dar cuenta de un proceso de contacto y confrontación entre lenguajes, que toma como punto de partida el problema de la traducción de términos nuevos, pero que en última instancia busca entender cómo se construye legitimidad discursiva en un contexto de disputa ideológica y política. En este sentido, Liu muestra que la traducción no es un evento neutral, al margen de los intereses en pugna en las contiendas políticas e ideológicas. Por el contrario,

la traducción es el sitio mismo de tales luchas, donde el lenguaje invitado (guest language) [en este caso, el japonés moderno y las lenguas europeas] es obligado a encontrarse con el lenguaje anfitrión (host lenguaje) [en este caso, el chino], donde las diferencias irreducibles entre ambos se dejan afuera, las autoridades son invocadas o desafiadas, las ambigüedades se crean o se disuelven, y así sucesivamente, hasta que nuevas palabras y significados emergen en el lenguaje anfitrión mismo (Liu, 1995, p. 26).

En un proceso continuo de contactos e intercambios, el japonés moderno utilizó los caracteres chinos de su sistema de escritura (kanjis) para traducir palabras de los idiomas europeos. Algunos de estos neologismos luego fueron importados de vuelta por el idioma chino moderno con un cambio de significado radical o como préstamos de palabras o componentes sin equivalente previo en el chino clásico. Por ejemplo, en el campo del arte moderno en formación durante estos primeros años del siglo XX, la palabra china meishu (arte, 美术) apareció como un neologismo traducido del japonés bijutsu, que a su vez se formó como 
traducción del alemán kunst (arte). Meishu se compone de dos caracteres logográficos propiamente chinos: mei (belleza, 美) y shu (libro, 术), pero siguiendo la trayectoria que describe Liu, debe tomarse en los términos de un "equivalente sin identidad" en el sentido de Ricoeur. En el contexto de uso del chino, meishu puede hacer referencia a las "bellas artes" occidentales, pero no da cuenta del arte moderno chino (xiandai yishu，现代艺术) que se forma en este contexto histórico-temporal en oposición al arte erudito tradicional (wenrenhua, 文人化). Vemos así que cada concepto, palabra, signo, tiene un eco de sentidos, una trayectoria que debe ser socio-históricamente situada. Por esta razón, su traducción nunca puede ser absoluta sino sólo hipotética y presupuesta para explicar desde un lugar determinado un hecho, fenómeno o proceso.

Lydia Liu traduce e historiza las fuentes a partir de las cuales conduce su investigación, integrando en un mismo oficio dos dimensiones de trabajo con el lenguaje. Pone en práctica lo que mencionamos anteriormente con relación al cuestionamiento e historización de los "equivalentes supuestos" que se construyen en la traducción, pero también pone en contexto y discusión el uso de determinados conceptos explicativos para abordar las implicancias de los primeros contactos entre lenguas. Su interés por el problema de los efectos de legitimación que producen los discursos sobre “lo moderno" (xiandai, 现代) en China, la lleva a preguntarse cómo fue esta experiencia, cómo la gente imaginaba y hablaba sobre la condición xiandai china. Liu releva para dar cuenta de esto no sólo los neologismos, préstamos y nuevos modos de escritura que surgen en la época, sino que también muestra cómo en la experiencia de contacto con lo extranjero pero sobre todo en las innovaciones que se producen en el contexto local, ciertos discursos sobre lo moderno cobran predominio sobre otros.

Al incorporar nuevas palabras, conceptos e ideas, nos muestra Liu, se van creando nuevos sentidos entre la gente. Estos, a su vez, se materializan en prácticas, experiencias, discursos y lugares de acción concretos. Con el enriquecimiento del lenguaje surgen entonces nuevos modos de significar la realidad y por lo tanto, también nuevas maneras de definir lo que se percibe como "modernidad" (xiandaixing, 現代性), que aparece como un imperativo cambiante y con nuevos desafíos en términos políticos y sociales. Se trata de una realidad histórica compleja, cuyas condiciones no resultan meramente impuestas desde afuera por la irrupción y la presencia de los modos extranjeros en el país, una visión que había predominado en las corrientes historiográficas del período hasta bien entrada la segunda mitad del siglo XX.

Al considerar el producto de las traducciones como intentos de comprensión del otro y de inclusión de nuevos sentidos, el lenguaje ofreció una forma de mediación cultural que produjo efectos renovadores en el ámbito del pensamiento y la cultura de China. A pesar de la debilidad política del régimen nacionalista chino y de las relaciones de dominación que en lo económico y lo militar buscaron extender las potencias 
europeas, la recomposición cultural y la integración que buscaron muchos intelectuales chinos a partir del contacto con lo extranjero, resultarían fundamentales en el proceso de definición de su propia modernidad. En este sentido, las nuevas prácticas que surgieron a partir de las transformaciones del lenguaje no fueron solamente una experiencia concreta de lo moderno chino, sino también de la historia de sus contactos y confrontaciones con Occidente.

Por último, cabe mencionar que Liu muestra en su libro una operación historiográfica que en su modo de traducción-comprensión de su objeto de estudio nos recuerda el último momento del desplazamiento hermenéutico que propone Steiner en Después de Babel. El acto de esclarecer, trasladar y anexar la significación en el proceso de traducción concluye en un momento de compensación. Se establece una restitución, un equilibrio de fuerzas entre ambos extremos del puente que traza el traductor como mediador. El idioma chino incorpora (comprende y se apropia) de lo extranjero, pero las obras traducidas se ven compensadas a su vez (pues su capacidad expresiva es realzada, detallada e iluminada por quien la recibe). La experiencia xiandai china se comprende en la trama de Liu a la luz de estos intercambios recíprocos entre los lenguajes, las culturas y las personas. Esta forma de traducción no impone un punto de vista excluyente, una historia unilinear, sino que acepta la diferencia insuperable entre lo propio y lo extranjero. Lo relevante de este enfoque es que ve en esta condición precisamente la oportunidad de diálogo y transformación mutua, aun cuando esta comunicación se realice en un contexto histórico de profundas contiendas políticas e ideológicas.

\section{Conclusiones}

A partir de ciertas premisas teóricas de la filosofía del lenguaje, hemos tratado de argumentar aquí que sólo podemos pensar la realidad que estudiamos (ya sea un texto, un discurso, un hecho social inscripto en el presente o el pasado) a través del rol mediador que desempeña el lenguaje. Sobre esta base, consideramos que es posible conocer esa realidad y construir relaciones para interpretarla a través de un trabajo cuidadoso con las palabras y a nivel del sentido. Son esos signos materiales -con sus significados múltiples y cambiantes en el interior de una comunidad de hablantes- los que permiten hacer presente lo que está ausente. Las experiencias del tiempo son significadas a través del lenguaje, y esto tiene tanto para la traducción como para la historia una importancia fundamental. La necesidad de comprender y comunicar desde este lugar una determinada lectura del pasado, respetando la pluralidad de sentidos que es propia de la realidad humana, motivó el interés en este ensayo por exponer los modos en que la traducción, del 
mismo modo que la historia comporta un ejercicio de significación, de comprensión y de comunicación de sentidos.

$\mathrm{Si}$ "entender es traducir", como postula la tesis de Steiner, preguntarnos por los modos e implicancias de la traducción es una forma de acercamiento a los problemas que conciernen al desafío de comprender el sentido y las acciones de los otros (los actores sociales que investigamos), pero también de uno mismo como investigador. Traducir lo entendido, por lo tanto, es un ejercicio de pensar y escribir sobre el carácter del discurso, sobre el lugar y los modos de enunciación propios y ajenos.

El compromiso con la realidad que tenemos como investigadores es hacer explícito el lugar desde donde nos inscribimos para mirar la realidad, además de trabajar críticamente las herramientas del oficio. Así, se vuelve más claro que la reflexión sobre la traducción es inseparable de la experiencia misma de traducir. Se trata de dos instancias inseparables en el oficio de traducir, pero también en el de construir una trama histórica, pues en ambos casos el desafío de la investigación social puede aparecer bajo la misma pregunta: ¿cómo es posible traducir una visión del mundo?

Tal como lo ejemplifica la obra de Lydia Liu, el proceso de traducción (como construcción semántica) implica la voluntad y el trabajo del investigador por comprender el sentido del otro (traducido o por traducir), por comunicar la riqueza de su especificidad, facilitando el diálogo y entendimiento recíproco, permitiendo en definitiva el paso a la hospitalidad lingüística. Pero, ¿en qué medida lo traducido, el conocimiento que se obtiene de este proceso, puede ser generalizado? Si bien la historia, al igual que la traducción, aportan desde el presente nuevos modelos de inteligibilidad del mundo, su capacidad comprensiva no puede ser total. El diálogo entre China y Occidente, la riqueza de sentidos que surgen en el lenguaje a partir de sus confrontaciones y encuentros, se plantea entonces desde esta clave de lectura como un terreno fértil para conocer los intercambios sin invalidar las diferencias.

La escritura histórica o la lectura del traductor buscan superar una distancia que es insuperable, pero aquí aparece no sólo el fantasma de la pérdida y el renunciamiento sino también la "pulsión de traducir", enfrentando la riqueza que supone la diversidad y heterogeneidad de las lenguas. Ese deseo de pasar por la experiencia-prueba de lo extranjero, de la cual nos hablaba Ricoeur, ese interés "que va más allá de la imposición y de la utilidad", acaso sea el mismo deseo que sostiene el compromiso ético, político y humano que comporta la comunicación horizontal con el otro en el oficio de investigar. 


\section{Referencias bibliográficas}

BAJTIN, M. (1982). Estética de la creación verbal. México: Siglo XXI.

BARTHES, R. (1994). "El discurso de la historia" en El susurro del lenguaje. Barcelona: Paidós, pp. 163-177.

BENJAMIN, W. (1999). “La tarea del traductor” en Ensayos escogidos. México: Ed. Coyoacán, pp.77-88.

BURKE, P., Gil, A. J. L., \& Martín, A. F. (2003). Formas de hacer Historia. Madrid: Alianza Editorial.

CHARTIER, R. (2007). La historia o la lectura del tiempo. Barcelona: Gedisa, pp. 34-38.

DE CERTAU, M. (2006). La escritura de la historia, México: Universidad Iberoamericana.

DE LA PEZA, M.C. (2012). “Consideraciones sobre la traducción en la investigación horizontal” en Corona Berkin, S., Kaltmeier, Olaf. En diálogo. Metodologías horizontales en Ciencias Sociales y culturales. Barcelona: Gedisa.

---. (2010). "Investigación cualitativa y análisis del discurso" en Mejía Montes de Oca P., Juarez Nuñez J., Comboni Salinas, S. (coord.). El arte de investigar, México: UAM-Xochimilco.

DUARA, P. (1996). Rescuing history from the nation: Questioning narratives of modern China. Chicago: University of Chicago Press.

GRIMSON, A. (2000). Interculturalidad y comunicación. Buenos Aires: Editorial Norma.

GADAMER, H. G. (1998). Arte y verdad de la palabra, Cap. 4 "La diversidad de las lenguas y la comprensión del mundo". Barcelona: Paidós.

JAKOBSON, R. (1987). “On Linguistic Aspects of Translation” en Pomorska, K. y Rudy, S. (ed.) Language in Literature. Cambridge: Harvard University Press, pp. 428-435.

LIU, L. (1995). Translingual practice. Literature, national culture and translated modernity. China, 1900-1937. Standford University Press.

PEIRCE, Ch. (1987). Obra lógica semiótica. Madrid: Taurus.

RICOEUR, P. (1995). Tiempo y narración I. Configuración del tiempo en el relato histórico. México: Siglo XXI.

---. (1996). Tiempo y narración II. El tiempo narrado, México: Siglo XXI.

---. (2005). Sobre la traducción. Buenos Aires: Paidós.

STEINER, G. (1995). Después de Babel. Aspectos de lenguaje y traducción. México: Fondo de cultura económica.

VOLOSHINOV, V. (1976). El signo ideológico y la filosofía del lenguaje, Buenos Aires: Ediciones Nueva Visión. WHITE, H. (2003). El texto histórico como artefacto literario y otros escritos. Buenos Aires: Paidós, pp.107140. 